\title{
Local and systemic effects of endotoxin mastitis on the chemiluminescence of milk and blood neutrophils in dairy cows
}

\author{
Jalil MeHrZad, Hilde Dosogne, \\ Evelyne MeYer, Christian BurveniCH*
}

\begin{abstract}
Ghent University, Faculty of Veterinary Medicine, Department of Physiology, Biochemistry and Biometrics, Salisburylaan 133, 9820 Merelbeke, Belgium
\end{abstract}

(Received 10 October 2000; accepted 30 November 2000)

\begin{abstract}
The local and systemic effects of intramammary lipopolysaccharide (LPS) injection on the chemiluminescence (CL) of milk and blood polymorphonuclear leukocytes (PMN) were investigated in six healthy early lactation cows. Clinical signs of acute mastitis such as fever, increased heart rate and a decreased milk production were observed in all cows. Before LPS challenge, the CL activity of milk PMN was significantly lower than that of blood PMN $(P<0.01)$. A significant negative correlation was found between pre-challenge milk and blood PMN CL and, the decreased milk production in unchallenged quarters. The CL activity of milk PMN from LPS-injected quarters increased following LPS challenge, whereas it remained unchanged in control quarters. The CL activity of blood PMN showed a biphasic increase, with two peaks and a valley below pre-challenge CL activity $(P<0.01)$. At post-challenge hours $(\mathrm{PCH}) 6$ and 12, the CL activity of milk PMN from LPS-injected quarters exceeded that of blood PMN ( $P<0.05$ and $P<0.001$, respectively). The decreased CL activity of blood PMN and the enhanced CL activity of milk PMN during endotoxin-induced mastitis was reflected by changes in the shape of the CL curve. In blood PMN, a decrease of the second peak of the CL curve suggests that the myeloperoxidase (MPO) $-\mathrm{H}_{2} \mathrm{O}_{2}$ system is impaired during endotoxin-induced mastitis. In contrast, the MPO- $\mathrm{H}_{2} \mathrm{O}_{2}$ system was enhanced in milk PMN from challenged quarters. The highest duration and intensity of reactive oxygen intermediate (ROI) production was observed in milk PMN from LPS-injected quarters at PCH 12. The increased viability of PMN in LPS-injected quarters and to a lesser extent in control quarters suggests possible effects of both facilitated diapedesis and inflammatory mediators on milk PMN survival. In conclusion, our results suggest that a combination of local and systemic action of $E$. coli endotoxin is involved in the priming of milk PMN during mastitis.
\end{abstract}

chemiluminescence / polymorphonuclear leukocyte / lipopolysaccharide / milk / blood

* Correspondence and reprints

Tel.: (32) 926473 21; fax: (32) 926474 99; e-mail: christian.burvenich@rug.ac.be 
Résumé - Effets locaux et systémiques de l'endotoxine de mammite sur la chimioluminescence des neutrophiles isolés du lait et du sang des vaches laitières. Les effets locaux et systémiques de l'injection intramammaire de lipopolysaccharide (LPS) sur la chimioluminescence (CL) des polymorphonucléaires neutrophiles (PMN) isolés du lait et du sang ont été étudiés chez six vaches en début de lactation. Des signes cliniques de mammite aiguë tels que la fièvre, la fréquence cardiaque élevée et la production laitière diminuée ont été observés chez toutes les vaches. Avant l'infusion de LPS, la chimioluminescence des PMN isolés du lait était sensiblement plus basse que celle des PMN isolés du sang $(P<0,01)$. Une corrélation négative significative a été trouvée entre la CL des PMN isolés du lait et du sang avant injection et la production laitière diminuée dans les quartiers noninjectés. La CL des PMN isolés du sang montrait une courbe biphasique, avec deux pics et une baisse de l'activité CL à un niveau inférieur à celle observée avant injection $(P<0,01)$. Six et 12 heures après injection, la CL des PMN isolés du lait des quartiers ayant reçu une injection de LPS dépassait celle des PMN isolés du sang ( $P<0,05$ et $P<0,001$ respectivement). La CL des PMN du sang diminuée et la CL des PMN du lait augmentée pendant la mammite induite par l'endotoxine se traduisait par des changements de forme de la courbe de CL. Dans les PMN isolés du sang, une diminution du deuxième pic de la courbe de CL suggère que le système myélopéroxidase (MPO)- $\mathrm{H}_{2} \mathrm{O}_{2}$ a été inhibé au cours de la mammite induite par l'endotoxine. Au contraire, le MPO- $\mathrm{H}_{2} \mathrm{O}_{2}$ était élevé dans les PMN du lait isolés des quartiers injectés. On a observé que la durée et l'intensité de la production des intermédiaires réactifs de l'oxygène (ROI) étaient les plus élevés dans les PMN isolés du lait des quartiers injectés par le LPS, 12 heures après injection. La plus grande viabilité de PMN dans les quartiers injectés par le LPS et à un degré moindre dans les quartiers non-injectés suggère des effets possibles de la diapédèse facilitée et des médiateurs inflammatoires sur la survie des PMN du lait. En conclusion, nos résultats suggèrent que la combinaison des actions locales et systémiques des endotoxines d'E. coli peut être impliquée dans l'amorçage des PMN dans le lait au cours de la mammite.

chimioluminescence / leucocyte polymorphonucléaire / lipopolysaccharide / lait / sang

\section{INTRODUCTION}

Polymorphonuclear leukocytes (PMN) are important components of the cellular host defense in protecting cows against Escherichia coli infection within the mammary gland [5, 15, 19, 21, 39]. Acute E. coli mastitis in early lactating cows is sometimes accompanied by severe general clinical symptoms such as fever and a sudden decrease of milk production in non-injected (non-inflamed) quarters [16, 24, 37]. Large quantities of endotoxin (lipopolysaccharide, LPS) are released during E. coli mastitis upon killing of bacteria, as well as during the exponential phase of bacterial growth $[7,16]$. Many effects of $E$. coli mastitis can be mimicked by the E. coli endotoxin, suggesting that LPS plays an important role in the pathophysiology of coliform mastitis [7, $16,42]$. The endotoxin mastitis model, however, is only partially comparable to the $E$. coli model. Because systemic symptoms following intravenous and intramammary injection of LPS differ, it has been suggested that endogenous mediators other than endotoxin are released and resorbed from the inflamed udder [24, 25]. Nevertheless, the endotoxin model can be used to study the role of LPS in the pathogenesis of $E$. coli mastitis.

The intramammary defense against invading pathogens is highly dependent on the rate of PMN diapedesis into the infected quarters [16], their capacity to produce reactive oxygen intermediates (ROI) [15] and the number of circulating PMN prior to infection $[15,21,37,39]$. Chemiluminescence (CL) can be used to study the oxygen-dependent bactericidal system of PMN $[1,9,23,27]$. In healthy cows, milk PMN could be considered as rather ineffective cells, compared to circulating PMN, because of their short half-life time $(t 1 / 2= \pm 8 \mathrm{~h})$, the exhaustion of their intracellular glycogen reserve [28], the potential induction of 
apoptosis and their decreased ROI generation following diapedesis [35]. Although the CL of milk PMN is lower than their blood counterparts (Mehrzad et al., unpublished results), the resident milk PMN could play an important role in the intramammary defense system against invading bacteria and their endotoxins because a significant influx of PMN from the circulation is not observed until $8 \mathrm{~h}$ after infection. Therefore, in our study the pre-challenge CL activity of milk PMN was assessed in order to investigate the role of the resident PMN in milk in the pathogenesis of coliform mastitis.

During E. coli mastitis, the ROI production of blood PMN has been observed to decrease [15]. The ROI production of milk PMN during mastitis, however, is not well characterized. The kinetics of ROI generation by blood and especially milk PMN during coliform mastitis has not been investigated. In addition, comparison of the ROI production of PMN from infected- and noninfected quarters can provide an insight into the local and systemic effects on PMN function during coliform mastitis. The viability and the maturity of PMN were also determined to provide insight into the observed alterations in CL activity.

\section{MATERIALS AND METHODS}

This experiment has been approved by the ethical committee of the Faculty of Veterinary Medicine of Ghent University.

\subsection{Animals}

Six cows of the East-Flemish Red Pied breed in their first lactation were used between 20 and 35 days after calving. These cows were selected on the basis of 2 consecutive bacteriologically negative milk samples and a milk somatic cell count (SCC) of $<2 \times 10^{5} \cdot \mathrm{mL}^{-1}$ milk per individual quarter. Cows were transferred to individual stalls 1 week before the start of the experiment. They were fed a daily ration of approximately $8 \mathrm{~kg}$ of concentrate and had free access to water and hay. They were milked twice daily at 7 a.m. and 4 p.m. with a 4-quarter milking machine.

\subsection{LPS challenge}

Ten mg LPS from E. coli O111: B4 (Sigma Chemical Co., St Louis, MO, USA) was diluted in $100 \mathrm{~mL}$ pyrogen-free $9 \mathrm{~g} \cdot \mathrm{L}^{-1}$ saline solution and aliquoted in bottles of $5 \mathrm{~mL}$ LPS solution $(500 \mu \mathrm{g}$ in $5 \mathrm{~mL})$. All air was removed from the bottles by a sterile $\mathrm{N}_{2}$-flow. LPS solutions were stored at $-20{ }^{\circ} \mathrm{C}$ until use. Frozen LPS solutions were thawed immediately before a challenge experiment and $15 \mathrm{~mL}$ of pyrogen-free saline solution was added. Before LPS injection the teat ends were disinfected with ethanol (70\%) mixed with chlorohexidine. Endotoxin mastitis was induced - after the morning milking - into the left front and rear quarters by a single intramammary (i.mam) injection of $20 \mathrm{~mL}$ LPS solution per quarter $\left(25 \mu \mathrm{g} L P S \cdot \mathrm{mL}^{-1}\right.$, final concentration) using a sterile teat cannula. After injection, each quarter was massaged for $30 \mathrm{~s}$ to distribute the LPS solution throughout the gland.

\subsection{Milk and blood sampling}

Quarter milk samples were aseptically collected for isolation and determination of somatic cell count (SCC) at $24 \mathrm{~h}$ before, immediately before and at 6, 12, 24, 48, 72, $144,216 \mathrm{~h}$ following LPS injection. Peripheral blood $(80 \mathrm{~mL})$ was collected aseptically from each cow by venipuncture from the external jugular vein into evacuated tubes (Laboratory EGA, F-28210 Nogent-le-Roi, France) containing 125 i.u. heparin as an anticoagulant. The blood sampling was carried out subsequently after milk sampling at $24 \mathrm{~h}$ before, immediately before and at 
$6,12,24,48,72,144,216 \mathrm{~h}$ following LPS challenge.

\subsection{Clinical symptoms}

Measurements of rectal temperature (RT), heart rate (HR), rumen motility and clinical examination of the mammary gland were performed at the time of blood and milk sampling. Evening and morning milk were pooled to obtain daily milk production (MP). To assess the severity of LPSinduced mastitis, the MP loss at post-challenge hours ( $\mathrm{PCH}) 24$ compared to the pre-challenge MP was used.

\subsection{Cell counting in blood and milk}

The total number of circulating leukocytes and isolated cells from blood and milk were determined using an electronic particle counter (Coulter counter ZF, Coulter Electronics Ltd., Luton, UK). Forty microliters of whole blood or $25 \mu \mathrm{L}$ of isolated cell suspensions were diluted in $20 \mathrm{~mL}$ of isotonic counting solution (Isoton ${ }^{\circledR}$ II, Counter Electronics, D-47705 Krefeld, Germany). Two hundred microliters and $100 \mu \mathrm{L}$, respectively, lysis solution (containing $\left(\mathrm{g} \cdot \mathrm{L}^{-1}\right)$ KCN 3.3, sodium nitroprusside 1.1, quaternary ammonium salt 55; Zap-Oglobin ${ }^{\circledR}$; Coulter Electronics) was added to the suspensions of whole blood and isolated blood cells. No lysis solution was used for the isolated milk cells. Determination of the cell number was performed with optimized instrument settings using a dual threshold model. The lower size threshold $(\mathrm{Tl})$ for whole blood samples was set at $3 \mu \mathrm{m}$, whereas the $\mathrm{Tl}$ for isolated cells from milk and blood was set at $5 \mu \mathrm{m}$. The size of cells between $\mathrm{Tl}$ and 12 times $\mathrm{Tl}$ was used for the quantification of cells in the sample. Five hundred microliters of blank agent and the cell suspensions were placed in the counter. The counting procedure was performed in triplicate, the value of the blank was subtracted for each sample and the mean was calculated as the number of cells $\cdot \mathrm{mL}^{-1}$ of the original sample. The SCC was determined for each individual quarter by a Fluoro-optoelectronic cell counting procedure (Fossomatic ${ }^{\circledR} 360$; Foss Electronic, Eden Prairie, MN, USA).

\subsection{Isolation of PMN from milk}

Individual quarter milk samples (200 mL) were collected aseptically and subsequent isolation of cells was performed according to Dulin et al. [9] with minor modifications. Briefly, pooled milk of the 2 LPS-injected and the 2 non-injected quarters of each cow was filtered separately through a nylon filter $(40 \mu \mathrm{m}$ pore size) and diluted to $50 \%$ $\mathrm{v} / \mathrm{v}$ with cold phosphate-buffered saline (PBS; $0.01 \mathrm{M}$ Phosphate $\left(\mathrm{KH}_{2} \mathrm{PO}_{4^{-}}\right.$ $\mathrm{Na}_{2} \mathrm{HPO}_{4}$ ) $-0.15 \mathrm{M} \mathrm{NaCl}, \mathrm{pH}=7.2$ ). Fat was carefully removed after the first centrifugation $\left(600 \times g, 15 \mathrm{~min}, 4^{\circ} \mathrm{C}\right)$, and the pellet was washed twice in cold PBS and centrifuged at $300 \times g$ for $10 \mathrm{~min}$ and $200 \times$ $g$ for 15 min at $4{ }^{\circ} \mathrm{C}$. The cells were resuspended in Dulbecco's PBS (Gibco BRL, Life Technologies Inc., MD Gaithersburg, USA) supplemented with $0.5 \mathrm{mg} \cdot \mathrm{mL}^{-1}$ gelatin (DPBSG). After counting, the viability and percentage of PMN of the isolated milk cells was determined (see below), and the cells were finally resuspended in a concentration of $5 \times 10^{6}$ viable $\mathrm{PMN} \mathrm{mL}^{-1}$ in DPBSG solution.

\subsection{Isolation of PMN from blood}

Isolation of PMN from peripheral blood was performed using hypotonic lysis of erythrocytes according to Carlson and Kaneko [6]. After counting, the viability and percentage of PMN of the isolated blood cells were determined (see below), and the cells were finally resuspended in a concentration of $5 \times 10^{6}$ viable PMN. $\mathrm{mL}^{-1}$ in DPBSG. 


\subsection{Differentiation and viability of cells}

Differential cell counts on the isolates were performed on eosin-Giemsa (Hemacolor®, Merck, Germany) stained smears. Identification of the milk cells was based on morphological characteristics as described by McDonald and Anderson [26]. PMN were characterized by their multilobed or sometimes pycnotic dark-bluish stained nucleus. Macrophages (M) typically had a large size, a vacuolated nucleus and contained whitish fat globules in their cytoplasm. Lymphocytes (L) were either large with a low nucleus-cytoplasm ratio and a light blue stained nucleus or small with a high nucleus-cytoplasm ratio and a darkbluish stained nucleus. Epithelial cells (only in milk) were identified as large, polygonal, uniformly light-bluish stained cells. Differential leukocyte counts were also performed with light microscopy on whole blood and isolated blood cell smears stained with eosin-Giemsa as described by Hayhoe and Flemans [14]. PMN (both mature and immature), M, L and epithelial cells were identified on at least 200 cells per slide. The viability of PMN in isolated cells, both from blood and milk, was determined using trypan blue dye exclusion according to Colotta et al. [8].

\subsection{Chemiluminescence assay}

Luminol-enhanced PMA (phorbol 12myristate, 13-acetate)-stimulated cellular chemiluminescence (CL) was used to measure the CL activity of cells isolated from blood and milk of LPS-injected and noninjected quarters. Briefly, the CL was measured in duplicate during $30 \mathrm{~min}$ at $37{ }^{\circ} \mathrm{C}$ with a microtiterplate luminometer (type LB96P; EG\&G Berthold, Bad Wildbad, Germany), immediately after addition of $100 \mathrm{ng} \cdot \mathrm{mL}^{-1}$ PMA and $0.3 \mathrm{mM}$ luminol (5amino-2, 3-dihydro-1, 4-phthalazinedione, Sigma) to $2 \times 10^{6}$ cells $\cdot \mathrm{mL}^{-1}$ in a total volume of $200 \mu \mathrm{L}$ per well. Stock solutions of
PMA and luminol were prepared in dimethyl sulphoxide (DMSO) (Sigma) and always stored at $-20{ }^{\circ} \mathrm{C}$. The area under the curve (AUC) was calculated for the registered impulse rates (relative light unit (RLU) $\cdot \mathrm{s}^{-1}$ ) over the whole measurement period of 30 min. The CL response was expressed per $10^{3}$ viable PMN in each isolated cell sample.

The following formula was used to perform the corrections, where $\mathrm{Cl}=$ mean $\mathrm{RLU} \cdot \mathrm{s}^{-1}, 4 \times 10^{5}=$ total number of cells per well, \% PMN = total percentage of PMN in isolated cells, $\% \mathrm{~V}=$ percentage of viable PMN:

$$
\mathrm{CL}_{\mathrm{PMN}}=\frac{\mathrm{Cl}_{\text {isolated cells }} \times 10^{3}}{4 \times 10^{5} \times \% \mathrm{PMN} \times \% \mathrm{~V}} .
$$

The CL of blood PMN was calculated with the same formula as for milk PMN, applying the corrections described by Heyneman et al. [15] for eosinophils contributing to the ROI production in the samples, considering that the CL response of eosinophils is five times higher than that of PMN.

\subsection{Shape of the CL curve}

To assess the kinetics of ROI generation during endotoxin mastitis, the profiles of cellular ROI production of milk and blood PMN were performed before the challenge $(-24 \mathrm{~h})$ and at PCH 12 in all cows.

\subsection{Statistical analyses}

The Statistix program package (version 4.1, Analytical Software, Tallahassee, FL, USA) was used for the statistical analyses. Because the values of PMN characteristics following injection of LPS were not normally distributed, a Kruskal-Wallis test was used to compare blood and milk PMN characteristics and the effects of LPS mastitis. The time of sampling was a fixed factor, cows were a randomized factor, and their interaction term was the error term. 
Significance of the differences was determined at $P<0.05^{*}, P<0.01^{* *}$ and $P<$ $0.001 * * *$

Correlations between blood and milk PMN CL before LPS challenge, and between MP loss in non-challenged quarters and PMN functions before the challenge was assessed using linear regression.

\section{RESULTS}

\subsection{Clinical observations}

The intramammary administration of LPS induced an increase of RT and HR that peaked around PCH 6, as well as swelling and pain of the challenged quarters, appearance of flecks and milk leakage in LPSinjected quarters observed at PCH 3 to 6 (data not shown) for all cows. The MP was reduced by $49 \pm 6 \%$ in non-injected quarters and by $80 \pm 6 \%$ in LPS-injected quarters at $\mathrm{PCH} 24$. It was completely restored at $\mathrm{PCH}$ 72 and 96 in non-injected and injected quarters, respectively (Fig. 1). Between PCH 6 and 12, a sharp increase of SCC was observed in LPS-injected quarters. At PCH 12 the SCC value exceeded the maximal detection capacity of the method (Fig. 2).
The SCC in control quarters was not changed. Clinical signs of mastitis disappeared around PCH 72.

\subsection{Differentiation of $P M N$ in isolated milk cells}

Before LPS injection, the percentage of PMN in isolated milk cells was $57 \pm 2 \%$. Compared to pre-challenge values, the percentage of milk PMN increased significantly at PCH 6 and 12 in LPS-injected quarters $(P<0.001)$ and to a lesser extent in noninjected quarters $(P<0.05)$ (Tab. I). In noninjected quarters the percentage of PMN returned to pre-challenge values at $\mathrm{PCH} 72$. The percentage of milk PMN in LPSinjected quarters also decreased, but remained higher than pre-injection values $(P<0.01)$ until $216 \mathrm{~h}$ after the challenge.

\subsection{Number and differentiation of blood cells}

Leukopenia was observed between $\mathrm{PCH}$ 6 and 12 reaching a minimum at $\mathrm{PCH} 6$ (Fig. 2). This was followed by leukocytosis from PCH 24 to 48. At PCH 6, band cells

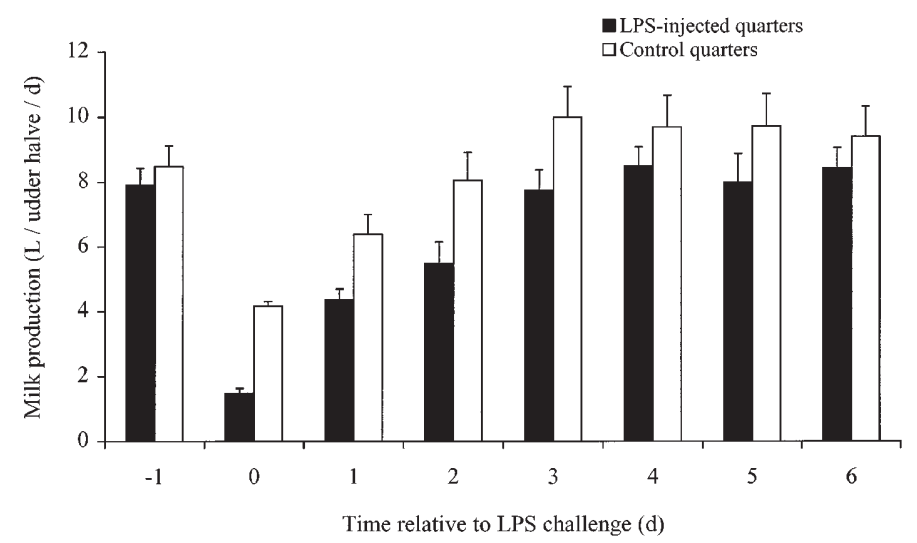

Figure 1. Daily milk production (liters/udder halve) from the LPS-injected (ם) and non-injected $(\square)$ quarters of cows during LPS mastitis. Values are the means \pm SEM of 6 cows. Time $0=$ day of LPS challenge. 


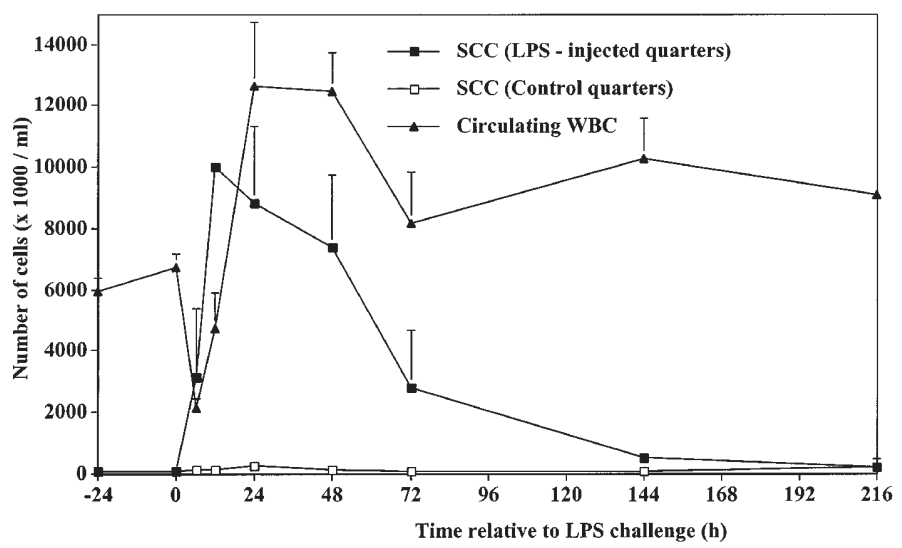

Figure 2. Changes in somatic cell count (SCC) of LPS-injected ( $\square$ ) and non-injected ( $\square$ ) quarters and in total WBC $(\boldsymbol{\Delta})$ of cows during experimentally induced LPS mastitis. Data are means \pm SEM of 6 cows.

appeared in the circulation and a peak of immature neutrophils, which was $47 \%$ of total isolated neutrophils, was seen at PCH 12 (Tab. I). Metamyelocytes were observed in the circulation at PCH 6 to 48 (Tab. I). A positive correlation was found between the percentage of immature neutrophils in whole blood and in isolated blood cells $(r$ $=0.92 ; P<0.001 ; n=56)$.

\subsection{CL of milk and blood PMN}

Compared to pre-challenge values, the CL activity in isolated milk PMN from LPSinjected quarters increased by $28 \pm 4 \%$ and $37 \pm 4 \%(P<0.001)$ at PCH 6 and 12 , respectively (Fig. 3). At PCH 6 and 12, the CL activity of milk PMN superseded that of blood PMN $(P<0.05$ and $P<0.001$,

Table I. Percentage of isolated milk PMN from LPS-injected and non-injected quarters, of PMN and of immature neutrophils (sum of band cells, myelocytes and metamyelocytes) isolated from blood. Values are the means \pm SEM of 6 cows. The level of significance is indicated with asterisks ${ }^{*}: P<$ $0.05, * *: P<0.01$ and $* * *: P<0.001)$. Time $0=$ day of LPS challenge.

\begin{tabular}{lcccc}
\hline \multirow{2}{*}{$\begin{array}{l}\text { Time relative } \\
\text { to challenge }(\mathrm{h})\end{array}$} & $\begin{array}{c}\text { MPS-injected } \\
\text { quarters }\end{array}$ & $\begin{array}{c}\text { Non-injected } \\
\text { quarters }\end{array}$ & $\begin{array}{c}\text { Blood PMN } \\
(\%)\end{array}$ & $\begin{array}{c}\text { Immature neutrophils } \\
\text { in blood }(\%)\end{array}$ \\
\hline-24 & $55 \pm 1.1$ & $56 \pm 0.9$ & $82 \pm 4$ & $0.2 \pm 0.1$ \\
0 & $60 \pm 0.6$ & $60 \pm 1.5$ & $83 \pm 4$ & $0.2 \pm 0.1$ \\
6 & $92 \pm 0.7 * *$ & $71 \pm 0.7 *$ & $71 \pm 4 *$ & $10 \pm 1 *$ \\
12 & $98 \pm 0.8 * * *$ & $69 \pm 0.9 *$ & $42 \pm 8 * * *$ & $38 \pm 9 * *$ \\
24 & $89 \pm 0.9 * *$ & $64 \pm 1.3$ & $76 \pm 7$ & $13 \pm 5 * *$ \\
48 & $84 \pm 1.9 * *$ & $65 \pm 2.1$ & $78 \pm 4$ & $8.0 \pm 2 *$ \\
72 & $74 \pm 1.4 * *$ & $62 \pm 1.3$ & $88 \pm 2$ & $4.0 \pm 0.3$ \\
144 & $73 \pm 2.2^{* *}$ & $55 \pm 3.0$ & $92 \pm 2$ & $1.0 \pm 0.3$ \\
216 & $73 \pm 2.3 * *$ & $56 \pm 2.6$ & $91 \pm 1$ & $0.4 \pm 0.2$ \\
\hline
\end{tabular}




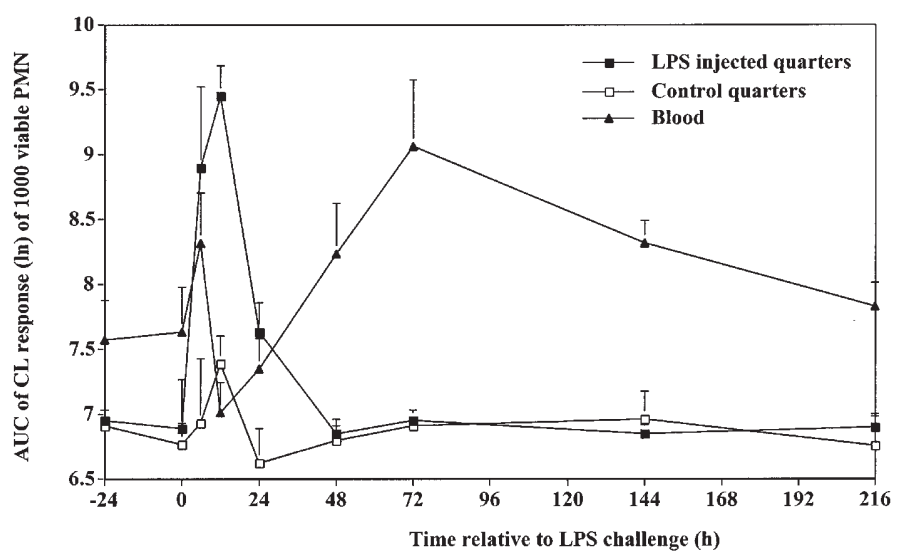

Figure 3. Chemiluminescence of stimulated milk PMN isolated from LPS-injected ( $\mathbf{\square})$ and noninjected $(\square)$ quarters and from blood $(\boldsymbol{\Delta})$ of cows during experimentally induced LPS mastitis. Values are the mean of 6 cows and error bars represent SEM.

respectively). The CL response of PMN isolated from LPS-injected quarters was higher than that of non-injected quarters at PCH 6 , 12 and $24(P<0.001, P<0.001$ and $P<$ $0.05)$, respectively. Pre-challenge values were again obtained at PCH 48 in LPSinjected quarters. The CL activity of isolated milk PMN of non-injected quarters did not change except for a slight increase at PCH 12. Before LPS challenge, the CL activity of blood PMN was higher than that of milk PMN $(P<0.01)$. The CL activity of PMN isolated from blood showed a biphasic increase following LPS challenge, with peaks at PCH 6 and 72 (Fig. 3). At $\mathrm{PCH} 12$ the CL activity was lower than before challenge time $(P<0.01)$. The valley between both CL activity peaks in the blood corresponded to the dramatic increase observed in the CL activity of milk PMN from LPS-injected quarters (Fig. 3). A negative correlation was found between the prechallenge CL activity of milk and blood PMN and MP loss in non-injected quarters $(r=-0.86, P<0.05$ and $r=-0.87, P<0.05$, respectively; $n=6$ ) (Tab. II). A significant positive correlation was found between pre-
Table II. Correlation between CL activity of milk and blood PMN, WBC and SCC averaged prior to LPS-challenge (d -4 to $d 0$ ) and milk production loss in control quarters at $d+1$ of the LPS challenge.

\begin{tabular}{lcc}
\hline Pre-challenge parameter & $r$ & $\begin{array}{c}\text { Statistical } \\
\text { significance }\end{array}$ \\
\hline CL of milk PMN & -0.86 & $P=0.018$ \\
SCC & -0.21 & NS $^{\mathrm{a}}$ \\
CL of blood PMN & -0.87 & $P=0.017$ \\
WBC & -0.37 & NS $^{\mathrm{a}}$ \\
\hline
\end{tabular}

${ }^{\mathrm{a}}$ Not significant.

challenge CL values of milk and blood PMN $(r=0.76 ; P<0.01 ; n=30)$.

\subsection{Shape of CL curves from blood and milk PMN}

Figure 4 shows representative CL profiles after stimulation with PMA of both blood and milk PMN at $-24 \mathrm{~h}$ (Fig. 4a), and at PCH 12 (Fig. 4b) following PMA stimulation. The ROI production in blood 


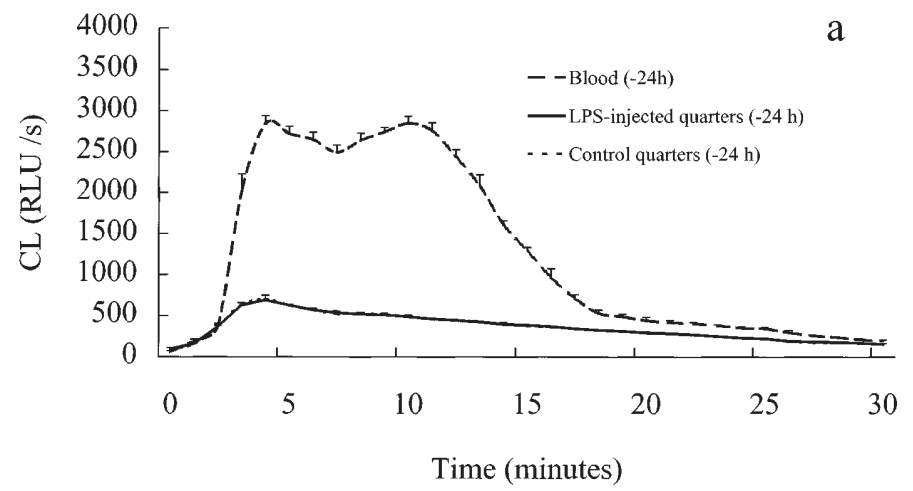

b

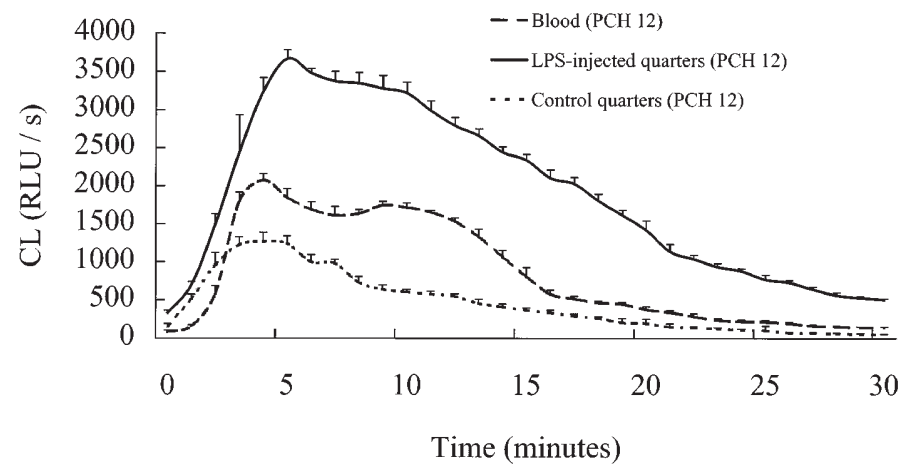

Figure 4. Chemiluminescence profile of stimulated-isolated blood and milk cells at $24 \mathrm{~h}$ before (a) and $12 \mathrm{~h}$ after experimentally induced LPS mastitis (b). Values are the mean of 6 cows and error bars represent SEM.

followed a typical biphasic pattern both before and after endotoxin mastitis with peaks after 4 and $12 \mathrm{~min}$. However, at PCH 12 the CL peaks were lower, which was more pronounced at the second peak. The intensity and duration of milk cell CL from LPS-injected quarters increased markedly at PCH 12 in comparison with the pre-challenge values. In contrast to the prechallenge values, the intensity and the duration of ROI production of milk cells from non-injected quarters were also increased. The CL of milk cells from inflamed quarters was higher than that of blood cells and of milk cells isolated from non-injected quarters at $\mathrm{PCH}$ 12. Although the intensity of
ROI production was higher, milk cells never demonstrated the biphasic pattern of the CL curve, which was typical of blood PMN.

\subsection{Viability of milk and blood PMN}

Before LPS challenge, the viability of PMN isolated from milk was $54 \pm 1 \%$. The viability of PMN isolated from milk of both LPS-injected and non-injected quarters increased at PCH 6 to 92 and $85 \%$, and at PCH 12 to 94 and $82 \%(P<0.001)$, respectively (Fig. 5). Viability was higher in PMN from LPS-injected quarters than from noninjected quarters $(P<0.01)$. Pre-challenge 


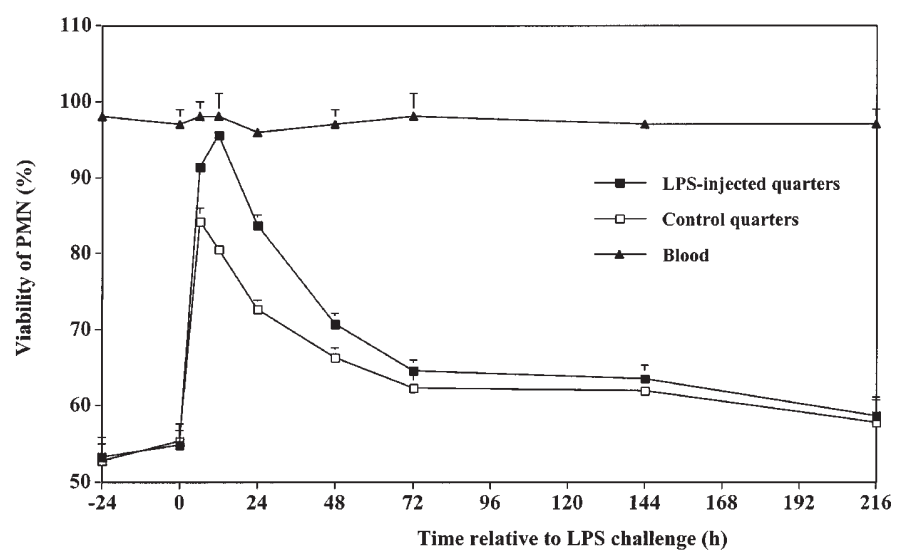

Figure 5. Viability of milk PMN isolated from LPS-injected ( $\square$ ) and non-injected ( $\square$ ) quarters and of blood ( $\mathbf{\Delta})$ of cows during experimentally induced LPS mastitis. Values are the mean of 6 cows and error bars represent SEM.

values were obtained again at $\mathrm{PCH} 216$. The viability of PMN isolated from blood varied between 96 and $97 \%$ and did not change significantly during the experiment (Fig. 5).

\section{DISCUSSION}

In the present study both local and systemic aspects of the nonspecific inflammatory response of the bovine mammary gland of early lactating cows were investigated in an acute endotoxin-induced mastitis model. This model was chosen because it mimics many responses occurring during natural $E$. coli mastitis [7, 16, 42]. Acute mastitis caused by LPS administration provoked local as well as systemic effects: inflammation of the LPS-injected quarters with an increase of SCC, decreased MP and fever and increased TPR (temperature, pulse and respiration). The lactating gland of the dairy cow is known to be sensitive to endotoxin at very low doses producing an inflammatory response [11, 32, 33]. It was not surprising, therefore, to observe a severe local reaction and clinical symptoms with higher doses of LPS as in our study. The magnitude of decreased MP, particularly in non-injected quarters, reflects the extent of systemic illness as demonstrated by Burvenich and Peeters [4] in lactating goats, and by Shuster et al. [33] in lactating cows. In spite of the observed systemic effects of LPS, it remains unclear which molecule(s) is/are directly involved in the uncontrolled pathogenesis of severely diseased cows during $E$. coli mastitis. Several recent studies suggest an important role of tumor necrosis factor- $\alpha$ $(\mathrm{TNF}-\alpha)$ in mediating the severity of the clinical symptoms during $E$. coli mastitis $[2,17]$. Milk production is undoubtedly related to the normal functionality of the mammary epithelium. However, LPS itself has no direct damaging effects on mammary epithelium [11]. Therefore, the decreased MP observed in inflamed quarters must have been caused by a factor other than a direct effect of LPS.

In this study a negative correlation was found between the pre-challenge ROI generation of milk PMN and MP loss in noninjected quarters. A possible explanation for this observation is that milk PMN may play a role in the direct detoxification of LPS by ROI production at the site of LPS injection. Consequently, LPS would be less available to initiate an inflammatory 
response and the subsequent induction of agalactia in non-injected quarters. Similarly, the ROI generation of blood PMN was as important as its milk counterparts. Blood PMN respiratory burst activity is indeed important for an efficient elimination of intramammary pathogens or LPS after migration into the mammary gland, as previously demonstrated in an $E$. coli mastitis model [15]. In addition, the detoxification of LPS by blood PMN could be important for the prevention of a severe systemic response to endotoxin.

Many host-derived cytokines such as interleukin-1 (IL-1), IL-6 [34] and TNF- $\alpha$ [18] are produced during LPS induced mastitis. They cause systemic effects such as fever and increase the bone marrow output of leukocytes to compensate for the decrease in the circulating pool [13]. Consequently, there is a transient increase in the circulation of the number of immature neutrophils as also observed in the present study. The host-derived cytokines also induce an increased capillary permeability, an increased permeability of the blood/milk barrier and a concomitant exudation of proteins such as bovine serum albumin (BSA) in lacteal secretions [20]. Increased permeability of the blood/milk barrier was indicated by the appearance of clots in milk at PCH 6. Between PCH 6 and 12 a large number of PMN having accumulated in the lacteal secretion of inflamed quarters resulted in a substantial increase of the SCC. The recruitment of PMN in the inflamed quarters, as reflected by the SCC [20], together with their increased ROI production are both important aspects of the defense mechanism against LPS during Gram-negative coliform mastitis.

The increased milk SCC in LPS-injected quarters coincided with an increased percentage, CL activity and viability of milk PMN, as well as a maximal decline of MP. At first sight, these phenomena could be explained by the enhanced migration of circulating PMN, resulting in a milk PMN viability and CL activity comparable to that of blood PMN. However, the CL activity of milk PMN exceeded that of blood PMN, suggesting an increased effectiveness of milk PMN upon accumulation in the inflamed udder following LPS exposure. According to Hoeben et al. [18], milk levels of host-derived cytokines such as TNF- $\alpha$ are higher than blood levels between $\mathrm{PCH} 4$ and 12 . Therefore, TNF- $\alpha$ might be involved in the observed increase in the milk PMN CL. Our observation is in agreement with the results of Watson et al. [40] who demonstrated that rat PMN isolated from LPS-treated bronchoalveolar lavage, showed a higher CL activity than circulating PMN.

The CL activity of isolated blood PMN was significantly increased at PCH 6. This increase could be due to priming effects of increased plasma concentrations of cytokines such as IL-1 and IL-6 in response to LPS [34]. Hoeben et al. [18] demonstrated that plasma TNF- $\alpha$ reached maximum levels at 4 to $8 \mathrm{~h}$ following intramammary injection with LPS. Indeed, IL- 1 and TNF- $\alpha$ can both prime circulating PMN to produce ROI following activation with PMA [10, $31,41]$. The second increase of the CL activity of blood PMN at PCH 72 could be due to the production of additional inflammatory mediators priming the newly released PMN from the bone marrow. It remains unclear which molecules are responsible for an enhanced ROI production of these PMN.

A decrease of the CL activity of circulating PMN was observed at PCH 12. Similar results were observed at PCH 18 during induced $E$. coli mastitis [15, 38]. This delay of $6 \mathrm{~h}$ in the decrease of respiratory burst activity of circulating PMN in the $E$. coli mastitis model with respect to the LPS model, can be explained by differences in the inflammatory response between endotoxin and E. coli challenge. The decreased blood PMN CL activity at PCH 12 was accompanied by an increased percentage of band neutrophils, metamyelocytes and myelocytes in circulation. This is similar to observations during $E$. coli-induced mastitis and can be ascribed to the indirect effect 
of LPS on the release of immature neutrophils from the bone marrow. The decreased respiratory burst activity of circulating PMN at PCH 12 can be explained by this increased immaturity. Indeed, immature PMN have a lower ROI production $[12,15]$.

The profiles of cellular ROI production before the challenge and at $\mathrm{PCH} 12$ showed remarkable differences. In general, the changes during endotoxin-induced mastitis were different in PMN from blood and from milk of challenged and non-injected quarters. More specifically, the changes in blood and milk PMN were reversed, with a decrease in the CL curve of blood PMN and an increase in that of milk PMN. The decreased intensity of ROI production of blood PMN was more pronounced at the second peak of the CL profile. According to Briheim et al. [3], both intra- and extracellular events contribute to the luminoldependent CL of human PMN. The first peak of the CL curve is probably the result of the initial extracellular reactions, whereas the second peak is the result of further intracellular reactions of the MPO- $\mathrm{H}_{2} \mathrm{O}_{2}$ system. Thus, our findings suggest that the observed decreased of PMN CL activity during endotoxin-induced mastitis is primarily due to a decrease activity of the MPO- $\mathrm{H}_{2} \mathrm{O}_{2}$ system. This could be explained by immaturity of neutrophils, as the MPO enzyme is not present in myeloblasts and immature neutrophils have a decreased MPO activity. The increased intensity and maximal duration of ROI production in the CL profile of milk PMN from inflamed quarters at $\mathrm{PCH} 12$ suggests an increase of both intra- and extracellular ROI production. These effects could be explained by the activation of mature PMN caused by the local production of inflammatory cytokines. Compared to inflamed quarters, the less strongly increased intensity and duration of ROI production of PMN from non-injected quarters, however, indicates that primed blood PMN may have been diapedesed into non-injected quarters. This suggests that inflammatory mediators were systemically released, leaking into the non-injected quarters, thereby possibly priming PMN for the slightly enhanced CL activity. In conclusion, it appears that the local production of inflammatory mediators is responsible for the priming of PMN between PCH 6 and 12 during endotoxin-induced mastitis, enabling milk PMN to exhibit a maximal bactericidal efficacy. The remarkable differences in the kinetics of milk and blood $\mathrm{PMN}$ function during mastitis require further study.

The viability, as opposed to necrosis, of milk PMN of LPS-injected quarters increased significantly between PCH 6 and 12. The modulation of bovine PMN survival in milk by LPS could be linked to the pathophysiology of endotoxin-induced mastitis, especially the kinetics of PMN diapedesis through the blood/milk barrier. As seen in our study, LPS induces a rapid migration of circulating PMN into the mammary gland. It also stimulates PMN diapedesis through the blood/milk barrier [29]. Indeed, LPS directly or indirectly [10] induces adherence of circulating PMN to the endothelium by the upregulation of $\mathrm{CD} 11 \mathrm{~b} / \mathrm{CD} 18$ [30]. The $\mathrm{CD} 11 \mathrm{~b} / \mathrm{CD} 18$ molecule is crucial to bovine PMN diapedesis across the blood/milk barrier [36]. In addition, the increased concentrations of BSA in milk from challenged quarters suggest an increased permeability of the blood/milk barrier. The enhanced diapedesis across the blood/milk barrier in combination with the increased permeability of this barrier could result in a significantly higher viability of milk PMN from LPSinjected quarters. Beyond this initial fast PMN influx into inflamed quarters, both LPS and some host-derived cytokines are known to delay apoptosis and subsequently increase viability of circulating PMN [8, 22]. Watson et al. [40] observed a delayed apoptosis and increased viability of PMN during LPS-induced migration in the lung of the rat. A less pronounced increase of milk PMN viability was observed in the non-injected quarters. Once again because of 
the absence of initial local mammary inflammation in the non-injected quarters, this increased viability of PMN was most likely caused by the systemic effects of LPS.

In conclusion, the strong enhancement of PMN CL activity observed in the LPSchallenged quarters is a consequence of both enhanced migration of blood PMN into the mammary gland, and priming by locally produced inflammatory mediators. The correlation between pre-challenge CL activity of the resident PMN in milk and the decrease of MP after LPS challenge suggests that the ROI production of milk PMN could play an important role in local neutralization of LPS and the subsequent inflammatory response prior to a significant influx of PMN in milk. Together with the correlation between blood and milk PMN CL activity, our findings suggest that low milk PMN CL activity could be considered as a risk factor for severe clinical coliform mastitis.

\section{ACKNOWLEDGEMENTS}

This study was supported by the Belgian Ministry of Small Enterprises and Agriculture (Grant S/5871), the Ministry of Science, Research and Technology of Iran and by the Belgian Fund for Scientific Research (FWO). The authors wish to thank L. De Bruyne and E. Vander Elstraeten for their technical assistance.

\section{REFERENCES}

[1] Allen R.C., Stjernholm R.L., Steele R.H., Evidence for the generation of an electronic excitation state(s) in human polymorphonuclear leukocytes and its participation in bactericidal activity, Biochem. Biophys. Res. Commun. 47 (1972) 679684.

[2] Blum J.W., Dosogne H., Hoeben D., Vangroenweghe F., Hammon H.M., Bruckmaier R.M., Burvenich C., Tumor necrosis factor- $\alpha$ and nitrite/nitrate responses during acute mastitis induced by Escherichia coli infection and endotoxin in dairy cows, Domest. Anim. Endocrinol. 19 (2000) 223-235.

[3] Briheim G., Stendahl O., Dahlgren C., Intra- and extracellular events in luminol-dependent chemi- luminescence of polymorphonuclear leukocytes, Infect. Immun. 45 (1984) 1-5.

[4] Burvenich C., Peeters G., Effect of experimentally induced mastitis on blood flow in the heterolateral gland in lactating goats, Zentralbl. Veterinaermed. A 30 (1983) 459-469.

[5] Burvenich C., Paape M.J., Guidry A.J., Miller R.H., Heyneman R.H., Kremer W.D.J., Brand A., Role of the neutrophil leukocyte in the local and systemic reactions during experimentally induced $E$. coli mastitis in cows immediately after calving, Vet. Q. 16 (1994) 45-49.

[6] Carlson G.P., Kaneko J.J., Isolation of leukocytes from bovine peripheral blood, Proc. Soc. Exp. Biol. Med. 142 (1973) 853-856.

[7] Carroll E.J., Schalm O.W., Lasmanis J., Experimentally coliform (Aerobacter aerogens) mastitis. Characteristics of the endotoxin and its role in pathogenesis, Am. J. Vet. Res. 25 (1964 ) 720726.

[8] Colotta F., Re F., Polentarutti N., Suzzani S., Mantovani A., Modulation of granulocyte survival and programmed cell death by cytokines and bacterial products, Blood 80 (1992) 20122020.

[9] Dulin A.M., Paape M.J., Nickerson S.C., Comparison of phagocytosis and chemiluminescence by blood and mammary gland neutrophils from multiparous and nulliparous cows, Am. J. Vet. Res. 49 (1988) 172-177.

[10] Ferrante A., Activation of neutrophils by interleukins- 1 and -2 and tumor necrosis factors, Immunol. Ser. 57 (1992) 417-436.

[11] Frost A.J., Brooker B.E., Hill A.W.W., The effect of Escherichia coli endotoxin and culture filtrate on the lactating bovine mammary gland, Aust. Vet. J. 61 (1984) 77-82.

[12] Glasser L., Fiederlein R.L., Functional differentiation of normal human neutrophils, Blood 69 (1987) 937-944.

[13] Goff J.P., Naito Y., Kehrli M.E.J.R., Hayer P., Daley M., Physiological effects of exogenous administration of interleukin-1ß in cows, Am. J. Vet. Res. 53 (1992) 1983-1987.

[14] Hayhoe F.G.J., Flemans R.J., An atlas of Haematological Cytology, Wolfe Publishing Ltd. G Barry Carruthers, M. D. London, 1969.

[15] Heyneman R., Burvenich C., Vercauteren R., Interaction between the respiratory burst activity of neutrophil leukocytes and experimentally induced Escherichia coli mastitis in cows, J. Dairy Sci. 73 (1990) 985-994.

[16] Hill A.W., Shears A.L., Hibbitt K.G., The pathogenesis of experimental Escherichia coli mastitis in newly calved dairy cows, Res. Vet. Sci. 26 (1979) 97-101.

[17] Hirvonen J., Eklund K., Teppo A.M., Huszenicza G., Kulcsar M., Saloniemi H., Pyörälä S., Acute phase response in dairy cows with 
experimentally induced Escherichia coli mastitis, Acta. Vet. Scand. 40 (1999) 35-46.

[18] Hoeben D., Burvenich C., Trevisi E., Bertoni G., Hamann J., Blum J.W., Role of endotoxin and $\mathrm{TNF}-\alpha$ in the pathogenesis of experimentally induced mastitis in periparturient cows, J. Dairy Res. 67 (2000) 503-514.

[19] Jain N.C., Neutrophil leukocytes and inflammation of the bovine mammary gland, Theriogenology 6 (1976) 153-173.

[20] Kehrli M.E.J.R., Shuster D.E., Factors affecting milk somatic cells and their role in health of the bovine mammary gland, J. Dairy Sci. 77 (1994) 619-675.

[21] Kremer W.D.J., Noordhuizen-Stassen E.N., Grommers F.J., Daemen A.J.J.M., Henricks P.A.J., Brand A., Burvenich C., Preinfection chemotactic response of blood polymorphoneuclear leukocytes to predict severity of Escherichia coli mastitis, J. Dairy Sci. 76 (1993) 1568-1574.

[22] Lee A., Whyte M.K.B., Haslett C., Inhibition of apoptosis and prolongation of neutrophil functional longevity by inflammatory mediators, J. Leukocyte Biol. 54 (1993) 283-288.

[23] Leino L., Paape M.J., Comparison of the chemiluminescence responses of bovine neutrophils to differently opsonized zymosan particles, Am. J. Vet. Res. 54 (1993) 1055-1059.

[24] Lohuis J.A.C.M., Verheijden J.H.M., Burvenich C., Van Miert A.S.J.P.A.M., Pathophysiological effects of endotoxins in ruminants. 1. Changes in body temperature and reticulo-rumen motility, and the effect of repeated administration, Vet. Q. 10 (1988) 109-116.

[25] Lohuis J.A.C.M., Verheijden J.H.M., Burvenich C., Van Miert A.S.J.P.A.M., Pathophysiological effects of endotoxins in ruminants. 2. Metabolic aspects, Vet. Q. 10 (1988) 117-125.

[26] McDonald J.S., Anderson A.J., Total and differential somatic cell counts in secretions from noninfected bovine mammary glands: The early nonlactating period, Am. J. Vet. Res. 42 (1981) 1360-1365.

[27] Mehrzad J., Meyer E., Hoeben D., Burvenich C., Optimalisation of a routine method to measure chemiluminescence of bovine polymorphonuclear leukocytes using a simple liquid scintillation counter, Egyptian J. Dairy Sci. 28 (2000) $73-84$

[28] Naidu T.G., Newbould F.H., Glycogen in leukocytes from bovine blood and milk, Can. J. Comp. Med. Vet. Sci. 37 (1973) 47-55

[29] Paape M.J., Lilius E.M., Wiitanen P.A., Kontis M.P., Miller R.H., Intramammary defense against infectious induced by Escherichia coli in cows, Am. J. Vet. Res. 57 (1996) 477-482.

[30] Roets E., Burvenich C., Diez A., Goddeeris B., Evaluation of the role of endotoxin and cortisol on modulation of CD18 adhesion receptors in cows with mastitis caused by Escherichia coli, Am. J. Vet. Res. 60 (1999) 534-540.
[31] Sample A.K., Czuprynski C.J., Priming and stimulation of bovine neutrophils by recombinant human interleukin-1 alpha and tumor necrosis factor alpha, J. Leukocyte Biol. 49 (1991) 107115.

[32] Schultze W.D., Paape M.J., Level of E. coli endotoxin required to reproduce acute coliform mastitis, J. Dairy Sci. 53 (1970) 671-672.

[33] Shuster D.E., Harmon R.J., Jackson J.A., Hemken R.W., Suppression of milk production during endotoxin-induced mastitis, J. Dairy Sci. 74 (1991) 3763-3774

[34] Shuster D.E., Kehrli M.E., Stevens M.G., Cytokine production during endotoxin-induced mastitis in lactating dairy cows, Am. J. Vet. Res. 54 (1993) 80-85.

[35] Smits E., Burvenich C., Guidry A.J., Heyneman R., Massart-Leen A., Diapedesis across mammary epithelium reduces phagocytic and oxydative burst of bovine neutrophils, Vet. Immunol. Immunopathol. 68 (1999) 169-179.

[36] Smits E., Burvenich C., Guidry A.J., MassartLeen A., Adhesion receptor CD11b/CD18 contributes to neutrophil diapedesis across the bovine blood-milk barrier, Vet. Immunol. Immunopathol. 73 (2000) 255-265.

[37] Vandeputte-Van Messom G., Burvenich C., Roets E., Massart-Leën A., Heyneman R., Kremer W.D.J., Brand A., Classification of newly calved cows into moderate and severe responders to experimentally induced Escherichia coli mastitis, J. Dairy Res. 60 (1993) 19-29.

[38] Van Oostveldt K., Burvenich C., Moreia da Silva F., Massart-Leën A., Respiratory burst activity in activated and unstimulated isolated bovine blood neutrophils during experimentally induced Escherichia coli mastitis, J. Dairy Res. 66 (1999) 375-383.

[39] Van Werven T., Noordhuizen-Stassen E.N., Daemen A.J.J.M., Schukken Y.H., Brand A. Burvenich C., Preinfection in vitro chemotaxis, phagocytosis, oxidative burst, and expression of CD11/CD18 receptors and their predictive capacity on the outcome of mastitis induced in dairy cows with Escherichia coli, J. Dairy Sci. 80 (1997) 67-74.

[40] Watson R.W.G., Rotstein O.D., Nathens A.B., Parodo N.J., Marshal J.C., Neutrophil apoptosis is modulated by endothelial transmigration and adhesion molecule engagement, J. Immunol. 158 (1997) 945-953.

[41] Wewers M.D., Rinehart J.J., She W.Z., Herzyk D.J., Hummel M.M., Kinney A., Davis W.B., Tumor necrosis factor infusion in humans prime neutrophils for hypochlorous acid production, Am. J. Physiol. 259 (1990) 276-282.

[42] Ziv G., Schultz W.D., Influence of intramammary infusion of polymayxin B on the clinicopathologic course of endotoxin-induced mastitis, Am. J. Vet. Res. 44 (1982) 1446-1450 